\title{
Investigating interactions from the children's perspective
} Introduction to a special issue on young children's interactive competence, participation and engagement in

\section{social activities}

\author{
Yumei Gan \\ Shanghai Jiao Tong University, China \\ yumei.gan@sjtu.edu.cn
}

Susan Danby

Queensland University of Technology, Australia

s.danby@qut.edu.au

\section{Introduction}

This idea for this special issue was initiated by an international symposium at the International Institute for Ethnomethodology and Conversation Analysis (IIEMCA) Conference, held in Mannheim, Germany in July 2019. The symposium, titled 'EMCA Studies of Children: Kids in Interaction', was strongly attended, and there was discussant commentary from Asta Cekaite (Sweden). The presenters were contacted and invited to contribute to this special issue. 
In this special issue, we propose the 'children's perspective' as a way to investigate social interactions involving children. By 'children's perspective', we focus on what children do in social interactions; that is, children's situated practices of everyday activities, including how they themselves display understanding of their roles in interaction, how their competence is shown in situated moments, and how they construct their own social relationships with others through their talk and other communicative resources. We bring together studies where young children use a range of languages, building social membership in locally produced cultures and settings, to explore their competence, participation and engagement. We show that examining social interactions from the children's perspectives contributes to the development of child-centred analysis and to understandings of children as agentic members of their social interactions and relationships, across diverse interactional contexts involving children.

\section{Children and children's perspectives}

In a range of everyday contexts, children are often seen and treated as different from adults. In addition to adults often treating children differently, so too do researchers often consider children as a special group (e.g. ethics applications requiring additional review when children are involved; cf. Danby \& Farrell, 2004; Black \& Busch, 2016). Some studies have demonstrated that social interactions may be different when children are involved. For example, adult-child interaction is explicitly mentioned as an apparent exception to the preference for self-repair in the field of conversation analysis (Schegloff et al., 1977, pp. 380-381). The unpublished paper by Garfinkel, Girton, Livingston and Sacks (1982) described a 'kids' culture', which highlights the conjecture that kids have their own culture and world. Their work focuses on kids' competences on the one hand, when interacting amongst their peers and, on the other hand, how adults and parents treat children as not-yet-competent participants. A growing body of research, however, shows that children can and do accomplish their social interactions using the same structural resources as adults. For example, Danby and Baker (2000) showed how boys used recycled turn beginnings to gain the conversational floor. Given that the participants were boys aged three to five years in the block area of a classroom (Danby, 2002; Danby \& Baker, 1998), it could have been assumed by adults, including the teacher, that the boys were talking over each other in a chaotic way.

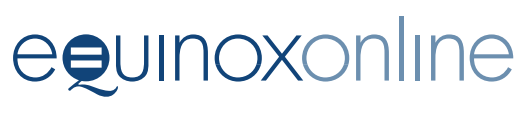


Close examination of the talk-in-interaction, though, found that the boys recycled their beginning turns exactly so that their complete message could be heard in its entirety on gaining the conversational floor.

In the last three decades, research 'about' and 'with' children is becoming increasingly valued and has produced various studies in this field. A diversity of disciplines has researched children, in disciplines including psychology, anthropology, linguistic, history, education, and sociology (e.g. Corsaro, 1985, 1997; Cromdal, 2001; Danby \& Baker, 1998; Goodwin, 1990; James \& Prout, 1997; Mackay, 1974; Piaget, 1932; Speier, 1971, 1973, 1976; Tomasello \& Farrar, 1986; Vygotsky, 1962, 1978). These studies provide important insights into understanding children's development, participation, and engagement in social lives. A research agenda that begins with the belief that children are active and competent participants in their everyday lives is a very different programme of research to one that focuses predominantly on children as being incomplete beings until they reach adulthood. We revisit some of this research, in order to show how differing theoretical understandings produces the lenses and language in which to understand the actions of children.

Beginning with influential cognitive and developmental psychology, we saw a program of research understandings that developed cognitive theory (Piaget, 1932) and sociocultural models (Erikson, 1963; Vygotsky, 1962). These theoretical understandings were developed in order to understand children's developmental changes, and children were described as developing with the idea that children are 'getting better' or 'becoming more competent' (for a critique, see Forrester, 2010, p. 45). The dominant understandings of children were driven through a research agenda focused on children's development, and not on how children demonstrated interactional competence and structural understandings of culture in their everyday worlds. In other words, children were treated are incompetent vis-à-vis adults.

This historical perspective of considering children as small adults (Aries, 1973) or as 'adults in miniature' (Almeida, 2011) was criticized from more recent sociological perspectives in not recognizing the competence of children to be interpreters of their own experiences (James \& Prout, 1997; Jenks, 1996; Mackay, 1974; Speier, 1976). In 'Sacks's conjecture' of kids' culture (Garfinkel et al., 1982, p. 6), Sacks noted that adults might be incompetent in accessing children's culture, and not the other way around. In other words, children may have their own methods to integrate

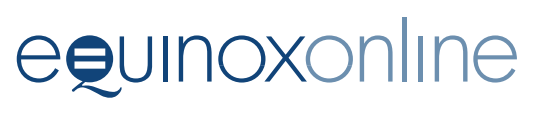


into social activities, and adults may be 'incompetent' and outsiders to understanding children's worlds. As Mackay (1974) pointed out, children are often represented through a mirror of an adult's view of how to treat children as incompetent beings. Mackay described this dominant view as children being seen as 'incomplete - immature, irrational, incompetent, asocial, acultural depending on whether you are a teacher, sociologist, anthropologist or psychologist. Adults, on the other hand, are complete - mature, rational, competent, social, and autonomous unless they are "acting-like-children"" (ibid., p. 181). By positing these understandings of children, Mackay (ibid.) proposed that children were competent interactants in their everyday world; and that in fact that children had to be, in order to understand how to interact with adults who saw them as incompetent. In the 1970 s, this differing view of children started to change how children were understood, through the sociological work of ethnomethodologists, including Garfinkel et al. (1982), Mackay (1974), Sacks (1972, 1982), and Speier (1971, 1973, 1976).

From the 1970s, the early ethnomethodologists focused their attention on understanding children as competent members of society. Ethnomethodology (EM) originated within sociology and was developed by Garfinkel (1967), who proposed to understand social order in the situated accomplishment of social activities. Conversation analysis (CA) shares a philosophical origin with EM. Developed by Sacks in collaboration with Schegloff and Jefferson (Sacks, 1992), and inspired by EM, the CA approach aims to study the social order through talk-in-interaction, focusing on the common-sense reasoning and practical theorizing present in interactional activities (Schegloff, 2007). The EMCA studies of Sacks (1972, 1982), Speier (1971, 1973, 1976) and Mackay (1974) were pioneering studies known as the sociology of childhood, followed by further investigations that studied children and treated them as 'already competent' (Baker, 1982; Bluebond-Langner,1978; Cromdal, 2001; Danby \& Baker, 1998; Evaldsson \& Corsaro, 1998; Hutchby and Moran-Ellis, 1998; Waksler, 1991). More recently, EMCA studies have explored a range of contexts in home and school, and within clinical settings (e.g. Bateman, 2015; Cekaite, 2010; Cekaite \& Holm, 2017; Church, 2009; Cobb-Moore, Danby \& Farrell, 2009; Filipi, 2009; Goodwin \& Kyratzis, 2007; Lamerichs, Danby, Bateman \& Ekberg, 2020; Theobald, 2013; Gardner \& Forrester, 2010; Goodwin, 2002; Keel, 2016). Taken together, this body of work has brought new ways of understanding the social lives of children with an emphasis

\section{evuinoxonlıne}


on 'overwhelmingly language saturated practices' as they go about their everyday social interactions (Cromdal, 2006, p. 465).

Alongside EMCA studies, in the 1990s emerged anthropological and ethnographic understandings of children in society, known as the new sociology of childhood (James \& Prout, 1997; Jenks, 1996; Qvortrup et al., 1994). This theoretical perspective was established as a new constructive perspective to study children, where James and Prout's Constructing and Reconstructing Childhood reconceptualized childhood as a social category. Scholars from this perspective encouraged treating children as 'objects of sociological investigation per se' (James \& Prout, 1997, p. 90); that is, studying children in their own right. These studies, similar to the ethnomethodological studies of children from the 1970s, argue that the child is an active agent in their everyday lives as well as a collective actor in their social lives with each other and with adults (Corsaro, 1985; Cook-Gumperz \& Kyratzis, 2001).

These sociology of childhood paradigms took as a shared point of interest children's culture in its own right. As Garfinkel and colleagues wrote:

this culture has the very specific feature that it is not accessible to persons who are not members. This is to say, it is not accessible to adults in the ways in which it is accessible to kids, and in the ways kids know about it [...] If the critical thing about a culture is this feature of competent membership, says Sacks, then it would seem that it can be said about kids' culture, in a very strong way, that it does have exactly this feature. By this he means that from the point of view of the kids' culture, ('from the kids' point of view'), the adult is an alumnus [...] Considering this, the adult is not merely a more competent person than the kid, but there has to be a very strong meaning when one says that the adult is an incompetent child. (Garfinkel et al., 1982, p. 7)

Black and Busch (2016, p. 219) point out, however, that 'even with changing views, children largely remain a silenced and invisible group ... Views about research relationships with children and their status and location in research must continue to be topics of discussions'. This view speaks to the origins of this conference symposium and associated special issue.

This special issue furthers these discussions from two aspects. First, we propose the 'children's perspective' as a way of conceptualizing and studying children's interactions. We aim to highlight the situated practices that children use in social lives. We discuss how we (as researchers)

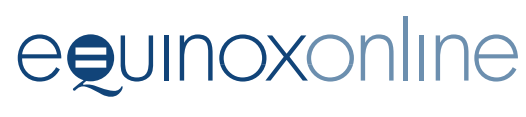


can avoid an adult-centred analysis to instead develop children-centred analysis by looking at how children orient to actions. Second, we address the issue of how young children form their actions; for example, how they initiate, respond, and design their moment-by-moment upfolding actions by mobilizing various communicative resources, including the use of talk, body, and materials in the environment.

\section{The contributions to this special issue}

This special issue consists of five articles. All studies draw on naturally occurring data and are informed by an EMCA approach. Through this special issue, we shed light on the organization of children's practices in a range of settings across different cultural and linguistic backgrounds. We have contributions from family interactions (e.g. Tam; Kim \& Crepaldi; Gan) to peer interactions in school (Houen \& Danby), as well as face-toface interaction and video-mediated communication (e.g. Gan). It is our hope that the similarities and variations across different contexts provide evidence that goes beyond single cases.

Catherine Linda Tam, in her article 'Children's demands for parental action', discusses the practices that young children use to exercise their authority towards their parents. Drawing on video recordings of everyday family interactions in South Africa, the author starts with a description of an instance where a parent makes demands of their child and pursues the child's compliance. The case arguably reveals the normative expectations of parental authority in family interactions. As the author continues to show, however, young children can actively negotiate the authority and deontic stances in the upfolding interactions. When the parents do not comply with children's demands, the children artfully pursue parental compliance. This article shows how domains of deontic authority are (re) negotiated in the moment-by-moment interactions, and also demonstrates young children's competence in understanding relational boundaries, and in creating situated agency to accomplish their own authorities.

Sandra Houen and Susan Danby, in their article, "Two's company, three's a crowd": Multi-modal engagement with objects', examine in detail a single case of a video recording of three preschool aged girls in a classroom in Australia. Through a multimodal conversation analysis, the authors show how children simultaneously form inclusion dyads and exclusion of another peer in their peer interactions. Their analysis shows that children

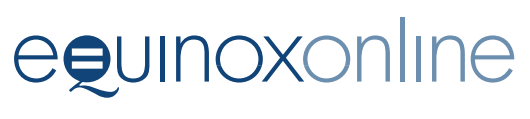


control the entry into their activity through limiting physical access to objects, multi-modal practices that divert attention away from the coveted objects, and assessments and sanctions around engagement with an object. Their findings provide important insights into the understanding of the complexity of interactional competence of children navigating social orders and social relationships. In particular, the article highlights how children protect their social relationships to ensure that the dyadic relationship remains secure.

Alessandra Fasulo, Iris Nomikou and Joanna Nye, in their paper, 'Action bids in children with speech impairments: The case of marking', investigate a practice, which they have called 'marking', observed in play interactions between parents and children with Down syndrome. Down syndrome occurs due to an abnormality of the chromosome 21 and affects children's intellectual development and physical characteristics. Previous research found that children with Down syndrome can use a greater range of 'natural' gestures, such as sign language for an alternative method of communication. In this study, Fasulo and colleagues examine these children's minimal turns that rely on prosody, embodied resources and indexicality to foreground events within an ongoing activity and convey a stance towards them (i.e. 'marking"). They show that markings can be both retrospective and prospective (i.e. referring to a just-occurred or an incipient event). As first pair parts, they are open action bids that prompt recipients to display their co-orientation towards the referent. Responses from parents (i.e. second markings) can take the form of repeats or expansions; after prospective marking the recipient can also add support to the incipient activity the child has marked. They discuss marking as the core constituent of a larger family of actions for 'sharing noteworthiness', but also as a designedly undetermined action bid with specific conversational uses for children and adults alike.

Yumei Gan, in her article, "Awww, she is feeding you": Young children's (dis)engagement in video calls with their migrant parents', examines video-mediated communication involving very young children (aged under three years old). Based on video recorded video calls between migrant parents and their left-behind children in China, her article discusses how these children spontaneously display engagement and disengagement during a video call. This study highlights that very young children deploy various communicative resources that orient towards the affordance of video-mediated communication technology, such as manoeuvring the

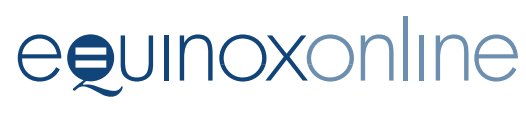


camera direction and initiating feeding and showing sequences. The analyses also illustrate that young children actively achieve disengagement in video calls through the artful use of language, body and the material world. These findings contribute to understanding children's situated practices with digital technology in family communication, and how children are active interlocutors who guide the adults' actions in moment-by-moment unfolding interactions.

Younhee Kim and Yvonne Crepaldi, in their article, "What? Olaf is the taxi driver?": Co-construction of spontaneous fantasy narrative in preschoolers' pretend play interaction', discuss the collaborative construction of fantasy narratives in interactions involving children. Drawing on data of pre-school-aged children's pretend play in both family interactions and children peer interactions, the authors conducted a close sequential analysis of how children construct and maintain the spontaneous narratives. Their findings show that children mobilize the shared knowledge of the fantasy character to create narratives, and also use communicative resources such as repetition, code-switching, to form the fantasy talk. This article makes visible how young children use practices to display their reasoning and how they orient to real life knowledge as resources to achieve their goals.

\section{About the guest editors}

Yumei Gan is an assistant professor at the School of Media and Communication at Shanghai Jiao Tong University (China). Her research interests include parentchild interaction, video-mediated communication and video analysis. She was the primary organizer of the 'EMCA studies of children' panel at the Conference of International Institution for Ethnomethodology and Conversation Analysis (IIECMA) in Mannheim, Germany, 2019. Her work has been published in Journal of Pragmatics, Discourse Studies and Proceedings of the SIGCHI Conference on Human Factors in Computing Systems (CHI '20).

Susan Danby is a professor in the School of Early Childhood and Inclusive Education, and director of the Australian Research Council Centre of Excellence for the Digital Child, at the Queensland University of Technology, Australia. Her research applies ethnomethodological and conversation analysis perspectives to investigating social interaction in children's peer groups as well as between children and adults in institutional settings such as classrooms and helplines. Her edited books include Disputes in Everyday Life (2012), Digital Childhoods (2018) and Children and Mental Health Talk: Perspectives on Social Competence (2020). She is on the editorial boards of Research on Children and Social Interaction and Classroom Discourse.

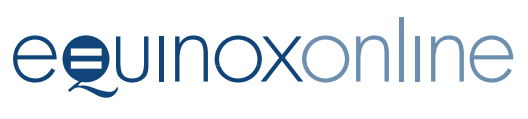




\section{References}

Almeida, D. (2011). Revisiting children's studies through the lens of sociology of childhood. UNISUL, 4(8), 473-484.

Aries, P. (1973). Centuries of Childhood. London: Penguin.

Baker, C. D. (1982). The adolescent as theorist: An interpretive view. Journal of Youth and Adolescence, 11(3), 167-181. https://doi.org/10.1007/bf01537465

Bateman, A. (2015). Conversation Analysis and Early Childhood Education: The Co-Production of Knowledge and Relationships. Farnham: Ashgate.

Black, A. L. \& Busch, G. (2016). Understanding and influencing research with children. In B. Harreveld, M. Danaher, C. Lawson, B. A. Knight \& G. Busch (eds), Constructing Methodology for Qualitative Research (pp. 219-235). New York: Springer. https://doi.org/10.1057/978-1-137-59943-8

Bluebond-Langner, M. (1978). The Private Worlds of Dying Children. Princeton, NJ: Princeton University Press.

Cekaite, A. (2010). Shepherding the child: Embodied directive sequences in parent-child interactions. Text \& Talk, 30(1), 1-25. https://doi.org/10.1515/text. $\underline{2010.001}$

Cekaite, A. \& Holm, M. (2017). The comforting touch: tactile intimacy and talk in managing children's distress. Research on Language \& Social Interaction, 50(2), 109-127. https://doi.org/10.1080/08351813.2017.1301293

Church, A. (2009). Preference Organisation and Peer Disputes: How Young Children Resolve Conflict. Ashgate.

Cobb-Moore, C., Danby, S. \& Farrell, A. (2009). Young children as rule makers. Journal of Pragmatics, 41(8), 1477-1492. https://doi.org/10.1016/j.pragma. $\underline{2007.04 .013}$

Cook-Gumperz, J. \& Kyratzis, A., (2001). Child discourse. In D. Schiffrin et al. (eds), The Handbook of Discourse Analysis (pp. 590-611). Oxford: Basil Blackwell. https://doi.org/10.1002/9780470753460.ch31

Corsaro, W., (1985). Friendship and Peer Culture in the Early Years. Norwood: Ablex. Corsaro, W., (1997). The Sociology of Childhood. Thousand Oaks, CA: Pine Forge Press.

Cromdal, J. (2001). Can I be with? Negotiating play entry in a bilingual school. Journal of Pragmatics, 33(4), 515-543. https://doi.org/10.1016/s0378-2166(99) 00131-9

Cromdal, J. (2006). Socialization. In K. Brown (ed.), Encyclopedia of Language \& Linguistics, 2nd edition, vol. 11 (pp. 462-465). Oxford: Elsevier.

Danby, S. (2002). The communicative competence of young children. Australian Journal of Early Childhood, 27(3), 25-30. https://doi.org/10.1177/183693910 $\underline{202700306}$

Danby, S. \& Baker, C. (1998). How to be masculine in the block area. Childhood, 5(2), 151-175. https://doi.org/10.1177/0907568298005002004

Danby, S. \& Baker, C. (2000). Unravelling the fabric of social order in block area. In S. Hester \& D. Francis (eds), Local Educational Order: Ethnomethodological 
Studies of Knowledge in Action (pp. 91-140). Amsterdam: John Benjamins. https://doi.org/10.1075/pbns.73.05dan

Danby, S. \& Farrell, A. (2004). Accounting for young children's competence in educational research: New perspectives on research ethics. The Australian Educational Researcher, 31(3), 35-49. https://doi.org/10.1007/bf03249527

Erikson, E. H. (1963). Childhood and Society. New York: W. W. Norton \& Company. Evaldsson, A.-C. \& Corsaro, W. A. (1998). Play and games in the peer cultures of preschool and preadolescent children: An interpretative approach. Childhood, 5(4), 377-402. https://doi.org/10.1177/0907568298005004003

Filipi, A. (2009). Toddler and Parent Interaction: The Organisation of Gaze, Pointing and Vocalisation. Amsterdam: John Benjamins Publishing.

Forrester, M. (2010). Ethnomethodology and adult-child conversation: Whose development? In Gardner, H. \& Forrester, M. (eds.), Analysing Interactions in Childhood: Insights from Conversation Analysis (pp. 42-58). Chichester: John Wiley. https://doi.org/10.1177/1461445611425718d

Gardner, H. \& Forrester, M. (eds). (2010). Analysing Interactions in Childhood: Insights from Conversation Analysis. Chichester: John Wiley.

Garfinkel, H. (1967). Studies in Ethnomethodology. Englewood Cliffs, NJ: Prentice-Hall.

Garfinkel, H., Girton, G., Livingston, E. and Sacks H. (1982). Studies of kids' culture and kids' talk. Unpublished research project, University of California, Los Angeles, CA.

Goodwin, M. H. (1990). He-Said-She-Said: Talk as Social Organization among Black Children. Bloomington, IN: Indiana University Press.

Goodwin, M. H. (2002). Building power asymmetries in girls' interaction. Discourse \& Society, 13(6), 715-730. https://doi.org/10.1177/0957926502013006752

Goodwin, M. H. \& Kyratzis, A. (2007). Children socializing children: Practices for negotiating the social order among peers. Research on Language and Social Interaction, 40(4), 279-289. https://doi.org/10.1080/08351810701471260

Hutchby, I. \& Moran-Ellis, J. (1998). Situating Children's Social Competence. In I. Hutchby \& J. Moran-Ellis (eds), Children and Social Competence: Arenas of Action. London: Falmer Press.

James, A. \& Prout, A., (1997). Constructing and Reconstructing Childhood: Contemporary Issues in the Sociological Study of Childhood. London: Falmer Press. Jenks, C. (1996). Childhood. London: Routledge.

Keel, S. (2016). Socialization: Parent-Child Interaction in Everyday Life. London: Routledge.

Lamerichs, J., Danby, S., Bateman, A. \& Ekberg, S. (eds). (2020). Children and Mental Health Talk: Perspectives on Social Competence. Basingstoke: Palgrave Macmillan.

Mackay, R. W. (1974). Conceptions of children and models of socialization. In R. Turner (ed.), Ethnomethodology (pp. 180-193). Harmondsworth: Penguin Education.

Piaget, J. (1932). The Moral Judgement of the Child. New York: The Free Press.

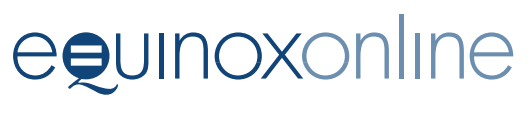


Qvortrup, J., Bardy, M., Sgritta, G. and Wintersberger, H. (eds). (1994). Childhood Matters: Social Theory, Practice and Politics. Aldershot: Avebury.

Sacks, H. (1972). On the analyzability of stories by children. In J. Gumperz \& D. Hymes (eds), Directions in Sociolinguistics (pp. 325-345). New York: Rinehart \& Winston.

Sacks, H. (1982). Button button who's got the button. Sociological Inquiry, 50(3-4), 318-327. https://doi.org/10.1111/j.1475-682x.1980.tb00025.x

Sacks, H. (1992). Lectures on Conversation. Oxford: Blackwell Publishers.

Schegloff, E. A. (2007). Sequence Organization in Interaction: A Primer in Conversation Analysis (Vol. 1). Cambridge: Cambridge University Press.

Schegloff, E. A., Jefferson, G. \& Sacks, H. (1977). The preference for selfcorrection in the organization of repair in conversation. Language, 53(2), 361-382. https://doi.org/10.2307/413107

Speier, M. (1971). The everyday world of the child. In J. D. Douglas (ed.), Understanding Everyday Life (pp. 188-217). London: Routledge.

Speier, M. (1973). How to Observe Face-to-Face Communication: A Sociological Introduction. Santa Monica, CA: Goodyear Publishing Company.

Speier, M. (1976). The child as conversationalist: some culture contact features of conversational interactions between adults and children. In M. Hammersley \& P. Woods (eds), The Process of Schooling: a Sociological Reader (pp. 98-103). London: Routledge \& Kegan Paul.

Theobald, M. (2013). Ideas as 'possessitives': Claims and counter claims in a playground dispute. Journal of Pragmatics, 45(1), 1-12. https://doi.org/10.1016/ j.pragma.2012.09.009

Tomasello, M. and Farrar, M. J. (1986). Joint attention and early language. Child Development, 57(6), 1454-1463. https://doi.org/10.2307/1130423

Vygotsky, L. (1962). Thought and Language. Cambridge, MA: MIT Press.

Vygotsky, L. (1978). Mind and Society: The Development of Higher Mental Processes. Cambridge, MA: Harvard University Press.

Waksler, F. C. (ed.). (1991). Studying the Social Worlds of Children: Sociological Readings. Basingstoke: Falmer Press. 